\title{
7 \\ Computer Aided Treatment of Diabetes
}

\author{
Christian Gapp, Wolfgang Reh, Karl Werner \\ Boehringer Mannheim GmbH, Sandhoferstr. 116, \\ D-68298 Mannheim, Germany, \\ Fax $+49 / 621-7594850$
}

\begin{abstract}
The authors describe the role of information technology (IT) in the field of monitoring and treating Diabetes. They discuss the requirements and present an integrated approach of a supplier of diagnostic and pharmaceutical products. Integration covers hand-held blood glucose (BG) measuring devices, procedures and tools for the management and analysis of patient BG data at home, education and training, and the professional area of general practitioners and hospitals with a distinguished range of documentation and communication needs.

The relevant IT trends are described and future directions of work are outlined.
\end{abstract}

\section{Keywords}

Healthcare Applications, User Interfaces, Diabetes Datasets

\section{INTRODUCTION}

Diabetes is a life threatening chronicle disease that affects about $5 \%$ of the population in industrialized countries. This number is rising. The treatment of diabetes accounts for about $10 \%$ of the health care costs in these countries.

There are two different types of diabetes: diabetes in young people, usually requiring insulin (IDDM), and diabetes in the elderly, for whom insulin injections are not always necessary (NIDDM). About $10 \%$ of all diabetics are IDDMs. If the blood sugar chronically is too high, severe and not-reversable organ damages will occur sooner or later: damages of the retina, kidneys, cardiovascular complications, early death. If the blood sugar is too low, the patient may die immediately (hypoglycemia). Up-to-date 
treatment of IDDM diabetes therefore aims at reaching near-normal blood glucose (BG) values. Fast and near real time monitoring of critical situations in the hands of patients are vital. The findings of the DCCT, a recent long term US-study, have proven the validity of this self-monitoring in significantly reducing late complications.

In 1989, the World Health Organization and the International Diabetes Federation (Europe) took part in proclaiming the European St. Vincent Declaration. Leading diabetologists declared treatment goals that are aiming at helping people with diabetes to reduce risk factors to a limit similar to that of non-diabetics. The treatment of diabetes is a complex, individual management process. Computer aided technologies are now recognized as potential key-tools for gathering data, for assessment and therapy adjustment.

The European research projects DIABCARD (see Engelbrecht (1994) and Pernice (1995)) and DiabCare Qnet (Laires, 1995) reflect this trend in the official research policy of the European Union in the context of Health Telematics. Efforts have been made to standardize Diabetes Datasets, for example in the form of the Basic Information Sheet (BIS) containing the diabetes relevant information.

\section{COMPUTER AIDED MANAGEMENT OF DIABETES}

Important for an effective treatment of IDDM is a working relationship between physician and patient. Since people with diabetes have to manage their daily life without direct assistance of a physician, methods are needed to help the patient document activities, and allow the physician to draw conclusions from the data that is generated between two visits of the patient (figure 1). Self-monitoring performed by the patient provides plenty of information: BG values as a function of time, quantity and time of food congestion, insulin type and dosage units, miscellaneous events such as exercise and insulin pump data. This information is designated as self-monitoring data and defines the metabolic situation. IDDM patients often measure their BG status 4 - 6 times per day. Thus, typically about 300-500 complex data records have to be analyzed, and decisions coping with all aspects of the metabolic situation have to be made fast and reliably. Critical trends and arising problems of daily or weekly metabolic rhythms have to be revealed and suitable data need to be provided for decision finding. Individual strategies for dose adjustment must be elaborated and realized by the physician and/or diabetes advisor together with the patient. Rapid feedback on the results of therapy changes are required. Suitable tools for a more reproducible and transparent data evaluation are needed. Graphical presentation becomes crucial for efficient therapy monitoring (figure 1). 


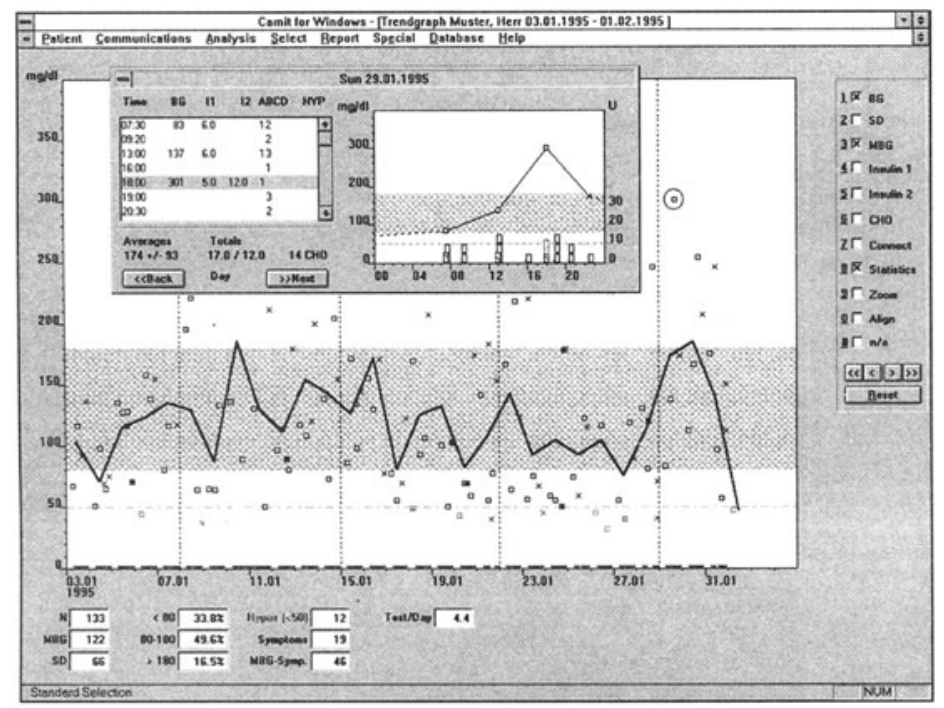

Figure 1 Trendgraph and Detail Analysis.

Quality Management will become of growing importance for professional diabetes institutions. Indicators for quality have to be defined, measured, documented and reviewed to monitor adequate cost/ performance ratios. Standardized sets of indicators such as the Basic Information Sheet should be used to gather outcome data as a starting point for increasing the process and structure quality of an institution. Ultimately, these data could be used to compare results of distinct, equivalent institutions (e. g. through voluntary benchmarking). IT-tools play a vital role on all levels of this implementation process. Networking between physicians, laboratories, and hospitals reduces costs of data collection and saves time in routine tasks. The target is to provide professional users with practical improvements of their internal processes.

To ensure its efficiency, an integrated IT-approach should cover the following aspects of diabetes treatment:

- self-monitoring of BG and documentation of the daily events by the patient;

- decision-support in accordance with the current situation by suitable presentation of self-monitoring data;

- administration and analysis of self-monitoring data;

- communication between physician and patient;

- assistance in training and education;

- improvement of diabetes therapy and monitoring of results;

- computerized documentation and quality management in diabetes institutions. 


\section{AN INTEGRATED SOLUTION}

Computer-based integrated solutions have been developed by Boehringer Mannheim (figure 2) and are now available in the market to physicians and patients:

- BG measuring instruments with electronic logbook functions: Accutrend ${ }^{\circledR} D M$;

- analysis software that allows a quick, graphical analysis of the patient data: Camit $^{\circledR}$ for Windows $^{T M}$;

- diabetes documentation software that keeps track of the findings according to the principles laid down in the St. Vincent Declaration: Diabcare ${ }^{\circledR}$ for Windows $^{T M}$.

Camit $^{\circledR}$ for Windows ${ }^{\mathrm{TM}}$ and Diabcare ${ }^{\circledR}$ for Windows ${ }^{\mathrm{TM}}$ can be operated with Windows 3.1, Windows 95, or Windows NT. These software packages use standard database systems and represent two different views on a pooled set of patient data. These data include the self-monitoring data of the patient and the treatment data of the doctor.All data are linked via patient master information.

The systems can be installed in a network environment and offer import and export facilities. The software design process applied object oriented technology. The systems are flexible and can be extended by further functions or reports as well as by software add-ons.

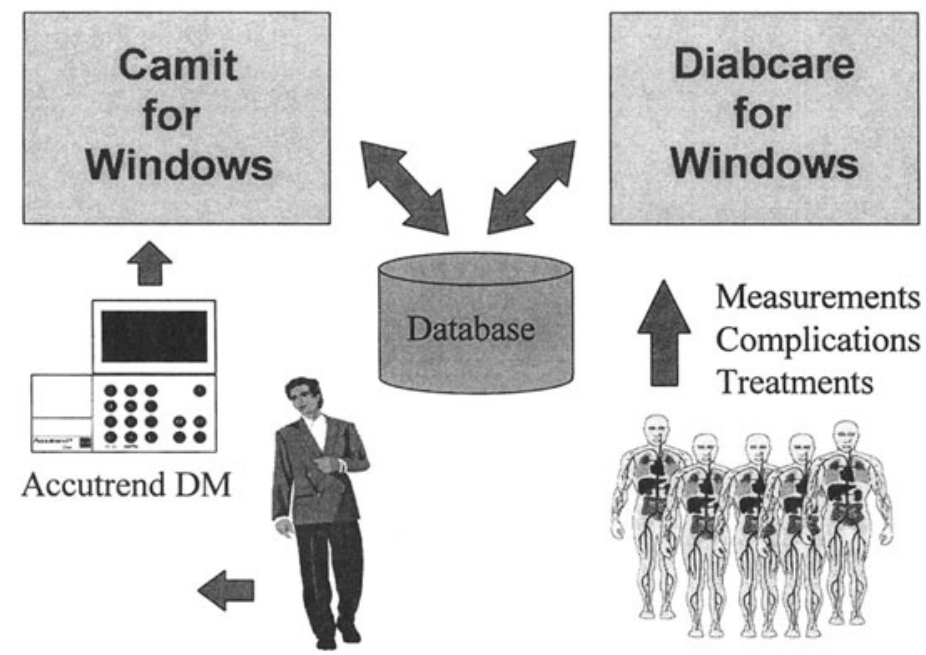

Figure 2 An Integrated Solution. 


\subsection{Meter and Logbook}

Key functions of $B G$ meters (likewise Accutrend $D M^{\circledR}$ in figure 3) are:

- fast measurement of BG;

- functions of an electronic diary;

- large display for graphical presentations;

- user-friendly interface with plaintext messages and easy data entry;

- stores and maintains the information relevant for dosage-decision including insulin, caloric intake, and exercise up to 500 complex data records;

- fast assesment of self-monitoring information by graphs, tables, and statistics;

- indicates trends and warnings in critical situations (e.g. hypoglycemia);

- PC interface for data download and meter customization.

Accutrend $\mathrm{DM}^{\circledR}$ implements first steps to assist decisions of the patient.

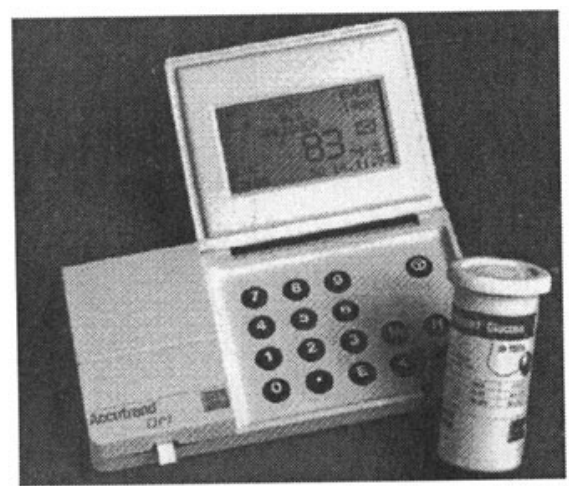

Figure 3 Meter and Electronic Logbook: Accutrend DM ${ }^{\circledR}$.

\subsection{Data Analysis}

Key functions of an analysis program (likewise Camit $^{\circledR}$ for Windows $^{T M}$ ) of self-monitoring data for patients and doctors are:

- reliable database for multiple patients;

- automatic identification of meters/patients and down-load of meter data;

- optimization for high-end meters including 'electronic diaries';

- interactive graphical analysis of BG data including daily and weekly rhythms;

- tools for analysis and improvement of insulin dosing scheme;

- data selections based on event codes and respective evaluation;

- user-definable reports for the patients;

- automizable reporting for doctors;

- safety (validity of data) and security (authenticity of data/documents, access rights, encryption techniques, etc.). 
Camit $^{\circledR}$ for Windows ${ }^{\mathrm{TM}}$ allows to establish standardized procedures in communication and data evaluation between physician and patient.

\subsection{Documentation and Outcome Monitoring}

Key functions of a diabetes documentation system (likewise Diabcare ${ }^{\circledR}$ for Windows ${ }^{T M}$ ) on professional sites are:

- reliable database for multiple patients;

- all clinical parameters relevant to diabetes;

- treatment scheme (oral antidiabetic drugs, insulin dosage scheme);

- complications with eyes, kidney, feet, and neuropathy;

- interactive graphical analysis of mid- and long-term data;

- user-definable reports;

- local statistics and report functions;

- support of outcome analysis and quality management including quality indicators;

- recall functions for patients based on visits and outcomes;

- import and export of data in standard formats (e.g. BDT, BIS);

- security and encryption mechanisms.

Diabcare ${ }^{\circledR}$ for Windows ${ }^{\mathrm{TM}}$ permits a long-term and strategic monitoring of therapy results and adaptation quality based on standardized data sets. The patient data is organized by visit dates.

\section{EXPERIENCES AND FURTHER INTEGRATION EFFORTS}

The described solution incorporates state-of-art capabilities of IT-tools for diabetes monitoring and treatment. The acceptance of IT by patients and diabetes professionals has strongly increased during the recent years. These tools have proven to ease routine work and to foster process improvements on professional sites.

Ideally, these devices and programs should be usable in stand-alone mode, as well as in a concurrent mode including local area networks and should be coupled with respect to patient master information .

Patients have an increasing demand of achieving assistance in education and training including information material, dietary information, user manuals, and effects of different insulin regimes in an electronic form.

Add-ons to these software packages for education and training of patients and for efficient local customizations of diabetes management in professional IT environments are strongly asked for.

Easy-to-use monitoring devices and better insulin infusion devices will make it straightforward to control system components with smart programs. The success of such systems is possible only through the acceptance by well-trained patients. Important approaches are evaluating algorithms for individual insulin adjustments based on patient data and optimizing the cooperation between insulin pump, pen, meter, and analysis software. 


\section{INTEROPERABILITY AND COMMUNICATION}

People with diabetes should participate in social life like non-diabetic people. To the individual this means mobility and flexibility. Communication technologies based on Smart Cards like DIABCARD and/or networks will be of high value to transfer medical data between centers and even across national borders. This requires interoperable system components based on future common standards (e.g. CEN TC 251). Today the healthcare IT environments are very fragmented and country-specific. Public networks like the Internet have the potential to serve as a source of information and as a communication medium for both patients and physicians. It is mandatory to implement technologies like software agents that help to reduce the overwhelming amount of information to the core that is of relevance to an individual.

\section{FUTURE TRENDS}

The Artificial Pancreas (AP) is on the agenda of all diabetes researchers in the world. It is not the discovery of the stone of wisdom that is needed for AP, but evolutions in a lot of distinct areas. These may include continuous non-invasive monitoring and closed loop systems with insulin dosing devices. Smart software components based on today`s experiences will play a key role on the way to realize an AP. More powerful hardware, advanced interface techniques (IR, RF), elaborated calibration, and control algorithms will be important ingredients.

\section{REFERENCES}

A. Pernice, H. Doare, O. Rienhoff (eds.): Healthcare Card Systems, EUROCARDS Concerted Action, Results and Recommendations, Studies in Health Technology and Informatics, Vol. 22, IOS Press, 1995.

R. Engelbrecht et. al: Smart Cards as Communication Tools in Health Information Systems, 13th World Computer Congress, Volume 2, p. 541 ff, IFIP 1994, Hamburg.

M. F. Laires, M. J. Ladeira, J. P. Christensen (eds.): Health in the New Communications Age, Studies in Health Technology and Informatics, Vol. 24, IOS Press, 1995. 


\section{BIOGRAPHY}

\section{Christian Gapp:}

$\mathrm{He}$ has a $\mathrm{PhD}$ in Physics. Today he is director for the evaluation of laboratory analyzers within the Labsystems Division of Boehringer Mannheim.

Wolfgang Reh:

He has a $\mathrm{PhD}$ in Mathematics and Computer Science. Presently he holds the position of a senior director for information systems within the Patient Care Division of Boehringer Mannheim.

Karl Werner:

Karl studied Electrical Engineering. Today he is project manager for diabetes IT products within the Patient Care Division of Boehringer Mannheim. 